\title{
Mil maneiras de "ser" e "estar" no mundo: da melancolia pequeno-burguesa à alegria do samba e da poesia popular ${ }^{1}$
}

João Augusto Neves Pires ${ }^{2}$

\begin{abstract}
Resumo
Este texto pretende, por meio de fontes documentais e produções culturais, apresentar dois pontos de vista, ou melhor, duas maneiras de "ser" e "estar" no mundo contemporâneo. Primeiro, analisa-se a melancolia da classe média, figurada no curta-metragem "Bom dia", do diretor Renato Cabral, para, em um segundo momento, contrastar tal perspectiva de vida com os elementos pulsantes na poesia de João Cabral de Melo Neto e nas canções de Cartola, produções reconhecidas como parte da cultura popular. Desta forma, pretende-se, com esse estudo, refletir sobre o modo como as classes populares e a classe média assumem a vida, cada uma em seu contexto e com experiências completamente diferentes, considerando a forma como a melancolia e a alegria aparecem em suas produções culturais.
\end{abstract}

\section{Palavras-chave}

Classe Média. Classes Populares. Culturas Populares.

1. Texto adaptado de uma primeira versão produzida e publicada para a sessão de críticas do Página Cultural. Disponível em: <http://paginacultural.com.br/cinema/diferentes-maneiras-de-ser-e-estar-no-mundo/>.

2. Graduando em História pela Universidade Federal de Uberlândia, bolsista pesquisador do Grupo de Pesquisa em Educação e Cultura Populares (GEPCPOP), membro do Núcleo de Pesquisa em Mídias na Educação (NUPEME) e da coordenação do Coletivo (RE) Ação, o qual realiza projetos de artes, tecnologias digitais e educação popular na zona leste da cidade de Uberlândia, Minas Gerais. E-mail: prof.joaoneves@gmail.com.. 


\title{
Thousand ways of "being" in the world: small bourgeois melancholy to joy of samba and popular poetry
}

João Augusto Neves Pires *

\begin{abstract}
Maintaining the current economic development, turning his eyes to the social development without losing focus of the sustainability of natural resources and don't penalize the future generations is the dilemma that many thinkers, politicians, economists, scientists and ordinary people bow down before. There's a world crisis that the solution is called Sustainable Development. This theme will support, in order to do an analysis about the reality of Paracatu City, Minas Gerais emphasizing the conflict between maroon communities and the mining site. Practical environmental exploitation are also shine through, appropriation of natural resources, as well as observation of the fragility of the new proposal: sustainability.
\end{abstract}

\section{Keywords}

Sustainability. Mining. Maroons.

* Graduating student in History at the Federal University of Uberlândia, researcher scholarship of Research Group in Education and Cultures Popular (GEPCPOP), member of the Research Centre Núcleo in Media in Education (NUPEME) and Coletivo (RE) Ação coordination, which performs art projects, digital tecnologies and popular education in the east zone of Uberlândia City, Minas Gerais. E-mail: prof.joaoneves@gmail.com 


\section{Despertar e problematizar sentimentos...}

Gostaria de dizer, antes de tudo, que as coisas que tentarei expor só foram possíveis pelo mergulho que o filme Bom-dia, de Renato Cabral, me proporcionou. Filme de grande ousadia técnica, estética e poética, no qual ator, diretor e câmera travaram um diálogo de grande sensibilidade artística. Por isso, antes das observações gostaria de parabenizar a todos(as) os(as) produtores(as) diretos e indiretos de tal filme. Principalmente o motorista Marildo, o qual foi lembrado nos créditos do curta - e que pessoalmente achei a atitude de colocar seu nome como equipe de produção bem bacana, pois demonstra como a obra é fruto de um esforço coletivo. Mas vamos lá... A poética do filme me deixou com uma pulga atrás da orelha e me fez pensar durante dias a respeito do que era todo aquele jogo de espelhos. Assim, fui construindo um raciocínio a partir das minhas experiências e leituras de mundo. Vamos à análise, então.

O filme retrata a história de um trabalhador (ou de todos os trabalhadores?) que, ao chegar a sua casa, após horas de cansativo trabalho, tendo que, novamente, abrir a porta para entrar em seu "lar" depara-se com uma dúvida: abrir ou não a porta, fugir ou aceitar a vida rotineira que ele (sobre) vive já há muitos anos? A partir desta incerteza instaurada na cena (Imagem 1) o roteiro do filme transita pelos conflitos vivenciados pelo personagem. Mostra os "sapos a serem engolidos" no expediente de trabalho, os conflitos intrafamiliares e os desejos sexuais e de consumo que atormentam o imaginário deste trabalhador. A mulher que engorda a cada dia, causando estado de nojo - sentimento construído a partir das imagens do filme -, e a vizinha "gostosinha" que alimenta seus desejos sexuais são pontos explorados como elementos de cena e de inquietação no decorrer da obra.

O filme não trabalha com diálogos, contudo o silêncio sempre é interrompido pelo som do relógio, do despertador ou de outro som agonizante que nos faz levantar e seguir na labuta. A escuridão, a sombra e a intensa claridade são elementos apropriados para aumentar a agonia e dissipar qualquer compreensão cômica ou romântica da situação. Enfim, o estado de agonia e tragédia, representações e sentimentos que comungam com imaginário social da classe média, se fazem presentes durante a obra.

"Uma porta. Uma chave. Se ele entrar, terá dito sim à vida medíocre de todos os dias. Se fugir, terá sua liberdade... e a redenção no inferno" (CABRAL, 2013) 3 . Descrição perfeita do filme e da visão de mundo que está impregnada em cada cena da obra desta obra arte. A mediocridade, a ânsia pela liberdade e a fuga do caótico inferno que representa a rotina são temores que pululam no imaginário da classe média, pequena-burguesia, do século XXI. As cenas da casa, da família, do trabalho, dos sonhos e, por fim, da porta (de entrada ou de saída) trazem à tona frustrações e perspectivas que afligem a vida mediana da personagem principal, encenado pelo ator Samuel Giacomelli. E são essas questões, ilustradas na Imagem 1, que gostaria de debater e refletir sobre a maneira que elas compõem o imaginário da classe média na contemporaneidade.

3. CABRAL. R. Bom-Dia no ar. Assista! Revisado em mar. 2013. Disponível em: <http://www.oruminante.com. $\mathrm{br} />$. Acesso em: 12 mar. 2013. 3 
Imagem 1: A escolha.

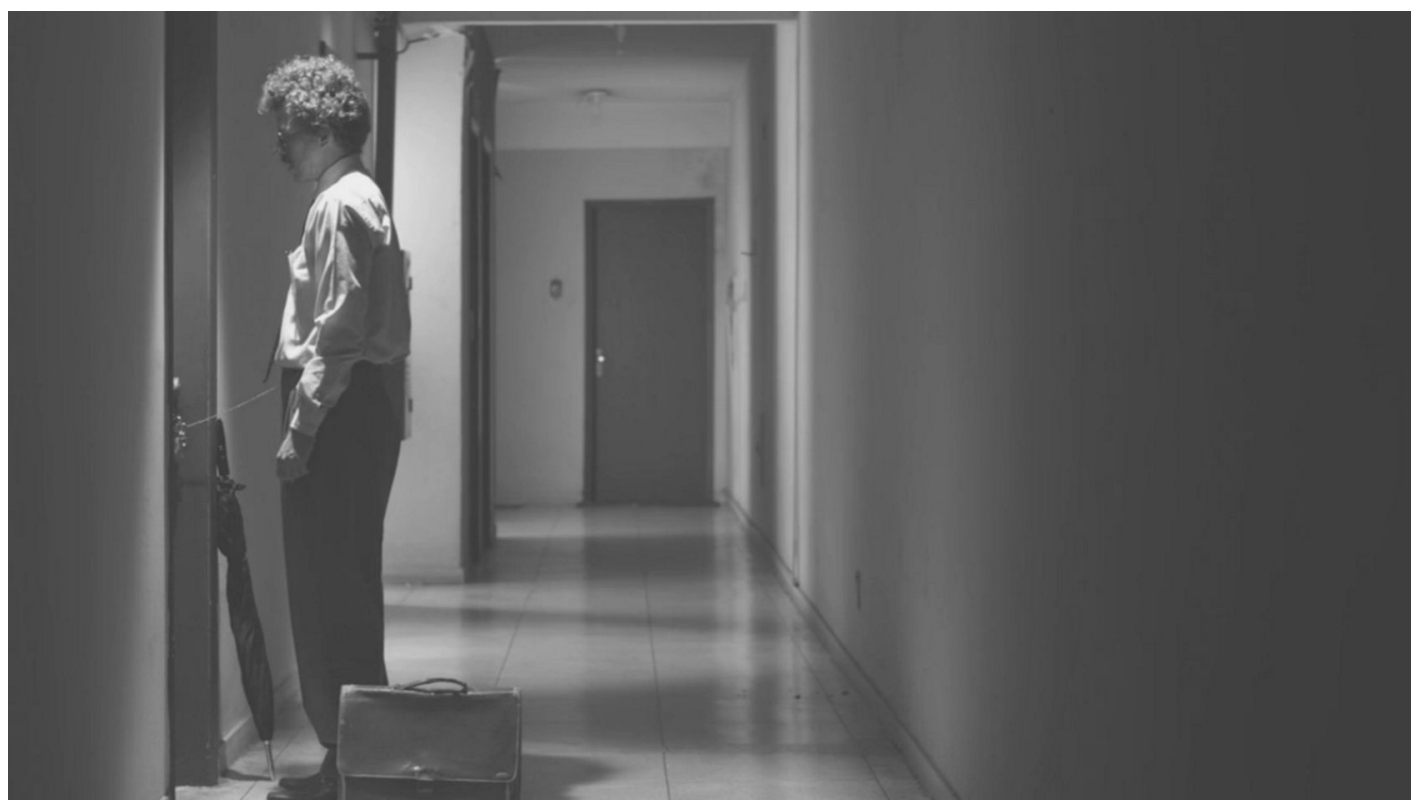

Fonte: Imagem extraída do filme "Bom dia".

Antes de pensarem que sou um "radicaloide" bobo, soltando rajadas e chavões esquerdistas, gostaria de refletir sobre a complexa classe média e sua conformação na sociedade atual. Apesar da minha dificuldade em trabalhar com conceitos fechados, correndo o risco de perder a dinâmica dos sujeitos históricos em determinados processos sociais, arriscarei me aprofundar no conceito trabalhado por Marilena Chauí (2013), em palestra conferida na Universidade de São Paulo (USP), a qual ilustra, de maneira caricatural e em poucas palavras, a situação incômoda em que se encontra a classe média em nosso país. Por não ser dona da propriedade privada dos meios de produção, ou melhor, do capital, tampouco ela representa a força de trabalho fabril ou campesina como os trabalhadores. Sendo estes campos historicamente definidos na estrutura social do sistema capitalista, a classe média ou pequena-burguesia está ali, no meio, entre os detentores dos meios de produção e aqueles que vendem a força de trabalho. Sobrevive em meio a sua fragmentação, raramente encontrando um interesse comum que a unifique. Flutua entre a esquerda majoritariamente composta por estudantes, funcionários públicos, professores e outras lideranças - e ao conservadorismo de direita.

Estando fora do núcleo econômico definidor do capitalismo, a classe média encontra-se também fora do núcleo do poder político: ela não detém o poder do Estado nem o poder social da classe trabalhadora organizada. Isso a coloca numa posição que a define menos por sua posição econômica e muito mais por seu lugar ideológico, e este tende a ser contraditório. (CHAUÍ, 2013, p. 131).

Resta-lhe, estando à margem deste núcleo definidor do sistema capitalista, agir no campo ideológico. Assim, será a classe média, na perspectiva de Chauí, o sustentáculo do aparato ideológico e simbólico na contemporaneidade. 
"A classe média tem um sonho!", sonho este dirigido pela noção de ordem e segurança - por isso, muitas vezes, age com conservadorismo sendo, desta forma, identificada como reacionária-, e dessa aspiração, ou melhor, deste sonho, que pode tornar-se pesadelo, há algo que a atormenta coagindo-a: o medo de ter que viver sob o jugo do patrão, de ver seus dias geridos por uma rotina do trabalho, de ver seus desejos não conquistados, de sua mulher engordar e não ser mais como as da capa de revista, enfim, da vida "medíocre" que Cabral imagina.

Por que digo que Cabral e os demais produtores do curta imaginam essa mediocridade? Ou esse inferno do cotidiano? De a mulher "fazer tudo sempre igual"? Porque este é um temor puramente pequeno-burguês, uma melancolia e um fatalismo assumidos, na maioria das vezes, pela classe média dentro da situação social de "fugacidade" e "liquidez" vivida pela sociedade contemporânea. Temor e (arrisco a dizer) corrosão de caráter que se forjou, segundo Sennett (2009), a partir das condições de tempo criadas no novo capitalismo, gerando um "conflito entre caráter e experiência, a experiência do tempo desconjuntado, ameaçando a capacidade das pessoas transformarem seus caracteres em narrativas sustentadas." (SENNET, 2009, p. 32)

\section{Pontos de vista}

Vamos avaliar, agora, essa afirmativa com outro enfoque, a partir da música $O$ sol nascerá do mestre Cartola, e do poema Morte e vida Severina, de João Cabral de Melo Neto. No início da canção, Cartola já resume de que maneira o homem e a mulher do morro, o (a) trabalhador (a) "levam a vida" apesar de suas tempestades. "A sorrir eu pretendo levar a vida, pois chorando eu vi a mocidade perdida" (CARTOLA, 1987). A mocidade pode ser tanto uma das famosas escolas de samba do Rio, como podemos interpretar a juventude ou anos da vida que foram perdidos em prantos. As classes populares, apesar da labuta diária, sempre souberam que, após a tempestade, "o sol nascerá" e que algo melhor virá, por isso hão de cantar, criar e sorrir com a vida e para a vida ou será isto um sofrimento. Em Uberlândia, percebe-se isso nos bairros populares de nossa cidade. No Morumbi e nos bairros de sua proximidade, por exemplo, sempre quando passo por lá nos finais de semana, os moradores estão na porta de sua casa e as avenidas principais preenchidas de gente escutando funk e sertanejo, demonstrando muita alegria. No documentário Beirão: um deficiente físico que surfa em ônibus (2011), também produzido por Cabral, o lendário hippie cadeirante da cidade de Uberlândia que pega beirão ${ }^{4}$ em ônibus, mostra ao seu interlocutor de que maneira ele tira "sarro da vida" e sente a "brisa do vento", "não chorando quando cai". Da mesma forma, diante da situação de miserabilidade, Severino, na obra de João Cabral de Melo Neto, questiona "que diferença faria se em vez de continuar, tomasse melhor saída: a de saltar, numa noite, fora da ponte e da vida?" (MELO NETO, 2012), afinal, não bastando os sofrimentos experimentados no sertão, na seca caatinga do nordeste, chega o retirante na cidade para continuar seu sofrimento no morro, na favela, na periferia, na superexploração da fábrica ou qualquer outro subemprego. Mas a resposta de Seu José, mestre carpina, vem certeira. Ilustra, ao fim do poema, o jeito das classes populares de encarar a vida:

Severino, retirante, / deixe agora que lhe diga: / eu não sei bem a resposta / da pergunta que fazia, / se não vale mais saltar / fora da ponte e da vida; / nem conheço essa resposta, / se quer mesmo que lhe diga; / é difícil defender, / só com palavras, a vida, / ainda mais quando ela

4. Expressão utilizada para designar a ação de andar em alta velocidade agarrado na parte dianteira dos ônibus urbanos. 
é, / esta que vê, severina; / mas se responder não pude / à pergunta que fazia, / ela, a vida, a respondeu / com sua presença viva. / E não há melhor resposta / que o espetáculo da vida: / vê-la desfiar seu fio, / que também se chama vida, / ver a fábrica que ela mesma, / teimosamente, se fabrica, / vê-la brotar como há pouco / em nova vida explodida; / mesmo quando é assim pequena / a explosão, como a ocorrida; / mesmo quando é uma explosão / como a de há pouco, franzina; / mesmo quando é a explosão / de uma vida severina. (MELO NETO, 2012)

Quer dizer, o sofrimento, a dor e a miséria são interpretados, pelas classes populares, como parte do espetáculo da vida, preenchida de morte e vida, do nascer e do morrer, enfim, uma contínua explosão que gera tristeza e alegria.

Outro exemplo que nos demonstra tal situação são os estudos de Bakhtin (1987) sobre cultura popular na Idade Média e no Renascimento. O autor dedica-se ao estudo da maneira pela qual as classes populares davam o tom de comicidade aos rituais e festividades religiosas e de que maneira o riso era a característica que prevalecia no "fazer cotidiano" das classes pobres da Europa medieval e renascentista. Apesar de Bakhtin não avançar na discussão sobre o entrelaçamento entre o medo e a alegria na cultura popular, o autor aponta importantes caminhos para que possamos identificar tais aspectos. A questão da comicidade do "populacho":

Ofereciam uma visão de mundo, do homem e das relações humanas totalmente diferentes, deliberadamente não oficial, exterior à Igreja e ao Estado; pareciam haver construído, ao lado do mundo oficial, um segundo mundo e uma segunda vida a das que os homem da Idade Média pertenciam em uma proporção maior ou menor em que vivenciavam em determinadas datas comemorativas. Isto criava uma espécie de dualidade de mundo. (BAKTHIN, 1987, p. 11)

Couberam, neste mundo "dupla face", destacado por Bakthin (1987), tanto as mediocridades da vida quanto as alegrias a serem inventadas ou as desgraças satirizadas. $\mathrm{O}$ "rir das desgraças dos outros" ou das próprias desgraças é algo comum no samba, na poesia, no funk, no churrasco, no trabalho e nas demais relações sociais das classes populares. E a tristeza? Conforme a letra de Festa da Penha, de Cartola (1999), espera-se até o domingo para poder colocar "uma camisa e um terno usado" que "alguém me empresta", pois "eu preciso ir à festa / Não brincarei / Quero fazer uma oração / Pedir à santa padroeira proteção". Apreendo desse trecho como a alegria e o medo estão intrínseca e intimamente interligados na cultura popular, pois, no mesmo momento em que se pede proteção à santa padroeira, também se festeja.

\section{Conclusão (?) ou a redenção}

Por outro lado - e quero aqui caminhar para a conclusão de minha crítica - o filme Bom-dia aspira e inspira um mundo trágico e pessimista, ele e seus produtores dialogam com sentimentos que se fazem hegemônicos em nossa sociedade. Renato Cabral, em seu site, ao se referir à sua obra e ao seu público mostra-nos como diretor e público são parte de um perfeito jogo de espelhos, em que o segundo, pontua Cabral, ao ver o filme:

Talvez ache um lixo ou só mais um desperdício de tempo. Mas se fizer sentido, e de alguma forma o filme te tocar, nos ajude a compartilhar mais uma vez esta história, que, de alguma forma, é a minha, mas também é a sua. (CABRAL, 2013).

Diria - agora sim podem me chamar de marxista clichê - que esta é uma obra bastante reacionária, pois ao final do curta, a fuga - o ato de matar a vizinha - representa a redenção, já que esta escolha é possível e permissível em nosso universo social e simbólico. As cenas do filme demonstram que há apenas duas escolhas 
a serem feitas e que ao optarmos pela redenção - que é a melhor escolha na perspectiva do diretor como veremos adiante - em nossas relações sociais, operamos com signos de prestígios, tendo, nesse sentido, como qualidade comum identificadora, posturas reacionárias, conservadoras, violentas, sexistas, machistas, por fim, diferentes atitudes autoritárias. Nesse sentido, a classe média está cansada de se deparar com a descrição dada por Cabral:

O sol está quente hoje. São 13h. Você deve estar no trabalho, cheio de barulhos e de gente; cheio da rotina de todos os dias, que transforma homens em armários de aço para sempre. (CABRAL, 2013).

Este mundo a torna mais melancólica e embrutecida, desvia seu caráter e sua história. Faz com que ela encare o mundo de maneira trágica e fatalista. Isso não quer dizer que tais características/qualidades não estejam presentes nas classes populares, mas que suas origens e experiências são diferentes, pois enquanto uma (sobre) vive em situação de miserabilidade e com pouco ou nenhum acesso aos bens materiais, a outra desfruta de uma situação melhor. As camadas pobres enxergam e lidam com tal situação de maneira diferente, às vezes com violência, em outras, com ares religiosos e/ou festivos. Criam e ressignificam o mundo em que vivem, dando a ele novos tons não alcançados pelos "de cima".

Revelemos a grande questão do filme. A redenção! O filme e as falas do diretor apontam para um caminho - que no meu ponto de vista é bastante infeliz. E, outra vez, é possível associar a obra à mentalidade dominante, já que uma escolha individual, de um só sujeito, é capaz de mudar tudo, mesmo que seja para pior. "Alguns, no entanto, conseguem se libertar e alcançar um pouco de alívio; quem sabe, até aquele mínimo de redenção, que seja no inferno" (CABRAL, 2013). Quer dizer: a liberdade individual como pressuposto da vida e privilégio de poucos que a conseguem. Com esta frase, Cabral conseguiu ilustrar a real tensão vivida pela sociedade na contemporaneidade a qual o diretor afirma compartilhar -, em que a liberdade é alcançada a partir do momento em que se consegue uma posição social melhor e mais favorável para determinado indivíduo e sua família. Ou seja, na sociedade do consumo resta-nos preservar o status quo ou se sujeitar ao inferno. E, ao contrário, das canções de Cartola, identificamos as concepções do filme e em nossa sociedade com a seguinte situação:

\begin{abstract}
Amanheceu mais uma vez. / É hora de acordar para vencer. / E ter o que falar. / Alguém para mandar. Uma vida pra ordenar. / Poder acumular e ai então viver, / viver e prosperar, mais nada a pensar. / Me myself and I. E assim permanecer, / credicard e status quo é tudo que penso ser, / ilusão é questionar. (DEAD FISH, 1999).
\end{abstract}

Por fim, pretendi com essa crítica demonstrar a maneira pela qual a classe média e as classes populares encaram a situação gerada pelas relações socais no capitalismo. Se por um lado a pequena burguesia (bancários, servidores públicos, comerciantes, advogados, professores, artistas e etc.) encara todo este mundo "experienciado" como trágico e deprimente, as classes populares, por outro lado, assumem a vida com muita graça e inexorabilidade, satirizando e sorrindo do (e para o) medo e da (para a) dor; ela vai "levando a vida", pois o espetáculo tecido pela vida - sábio Seu José, mestre carpina -, nos proporciona morte e vida, mesmo que seja ela "Severina". 


\section{Referências}

BAKHTIN, M. A cultura popular na Idade Média e no Renascimento: o contexto de François Rabelais. São Paulo: Hucitec, 1987.

BERÃO: um deficiente físico que surfa em ônibus. Dirigido por Renato Cabral. Uberlândia, Criação independente, 2011. 1 filme (9min), son., color.

BOM-DIA. Dirigido por Renato Cabral. Uberlândia: Imaginare Filmes, 2013. 1 filme (20min), son., color.

CABRAL. R. Bom-dia no ar. Assista! Postado em maio 2013. Disponível em: < http://www. oruminante.com.br/2013/05/02/bom-dia-no-ar-assista//>. Acesso em: 12 mar. 2013.

CARTOLA. O sol nascerá. In: CARTOLA. Cartola 80 anos. Rio de Janeiro: Independente, 1987. 1 disco sonoro. Faixa 3 (2min.).

CARTOLA. Festa de Penha. In: CARTOLA. Cartola, entre amigos. Rio de Janeiro, Funarte, 1999. 1 disco sonoro. Faixa 9 (56s)

CHAUÍ. M. Marilena Chauí sobre classe média. Disponível em: <http://www.youtube.com/ watch?v=9RbBPVPybpY>. Acesso em: 10 mar. 2013.

CHAUÍ, M. Uma nova classe trabalhadora. In: SADER, E. (Org.) Lula e Dilma: 10 anos de governos pós-neoliberais no Brasil. São Paulo: Boitempo; Rio de Janeiro: FLACSO Brasil, 2013.

DEAD FISH. Sonho Médio. In: DEAD FISH. Sonho Médio. São Paulo: Terceiro Mundo Produções Fonográficas, 1999. 1 disco sonoro. Faixa 3 (2min.).

GURVITCH, A. Bakhtin e sua teoria do carnaval. In: BREMMER, J.; ROODENBURG, H. (Org.). Uma história cultural do humor. Rio de Janeiro: Record, 2000.

MELO NETO, J. C. de. Morte e vida Severina. In: INEZ, C.; SECCHIN, A. C (Org.). O rio. Rio de Janeiro: Objetiva, 2012.

SENNETT, R. A corrosão do caráter: consequências pessoais do trabalho no novo capitalismo. Rio de Janeiro: Record, 2009.

Submetido em 28 de maio de 2013.

Aprovado em 24 de junho de 2013. 